\title{
PENGARUH PENDIDIKAN PAUD TERHADAP TINGKAT PERKEMBANGAN ANAK USIA TOODLER DI PAUD DIPONEGORO DSN. PUCANGANOM DS. SUKOREJO KEC. GURAH KAB. KEDIRI
}

\author{
Oleh : Susi Erna Wati, S.Kep.,Ns.M.Kes (NIDN 0709108202) \\ Siti Aizah, S.Kep.,Ns.M.Kes (NIDN 0714047701) \\ (Prodi DIII Keperawatan Fakultas Ilmu Kesehatan UN PGRI Kediri)
}

\begin{abstract}
Child development is the increased ability of the structure and function of the body is more complex. $48 \%$ of Indonesian children experiencing delays in development. The quality of child development is influenced by several factors, one of which is a stimulation or education. The method used is comparative analytic with cross sectional approach. The population is all children age (1-3 years) .In RW 05 Dsn. Pucanganom Ds. Sukorejo by 41 children. The sample was selected at the time the respondent was at the time of the study a number of 26 children Collecting data using KPSP sheet. Data were analyzed using Mann Whitney U-Test. The results showed that almost all (80\%) of children who attend early childhood development that are tailored and most (62.5\%) of children who do not follow early childhood development that are dubious. After doing the calculation using the Mann Whitney U-Test values obtained significant asymetri 0,017 . So we can conclude there is a difference between the development of children who attend early childhood education and do not follow the Early Childhood Education. Recommendations from this study is expected to hold a health officer introduction of the Early Childhood Education program for the improvement of child development at the Posyandu, polindes and other community activities.
\end{abstract}

Keywords: early childhood education, child development

\section{PENDAHULUAN}

1. Latar Belakang

Setiap tahapan perkembangan anak adalah masa penting. Setiap anak memiliki tahapan perkembangan yang berbeda - beda. Perlu ketelitian dari orang tua untuk mendorong anak agar mencapai puncak perkembangan optimal (gain moment) setiap anak. Masa toddler merupakan periode penting pada tumbuh kembang anak. Pada masa ini terjadi pertumbuhan dasar yang akan mempengaruhi dan menentukan perkembangan anak selanjutnya. Pada masa periode ini kritis ini, diperlukan rangsangan atau stimulasi yang berguna agar potensinya berkembang. Perkembangan anak akan optimal bila interaksi diusahakan sesuai dengan kebutuhan anak pada berbagai tahap perkembangannya (Kania, 2006). $\begin{array}{lcr}\text { Pendidikan Anak Usia Dini } & \text { (PAUD) } \\ \text { merupakan salah satu bentuk } \\ \text { penyelenggaraan pendidikan yang }\end{array}$ menitikberatkan pada peletakan dasar ke arah pertumbuhan dan perkembangan fisik (koordinasi motorik halus dan kasar), kecerdasan (daya pikir, daya cipta, kecerdasan emosi, kecerdasan spiritual), sosio emosional (sikap dan perilaku serta agama) bahasa dan komunikasi, sesuai dengan keunikan dan tahap-tahap perkembangan yang dilalui oleh anak usia dini. Salah satu cara untuk mendukung growthness dan pengembangan persyaratan anak adalah stimulasi pendidikan anak di usia dini (PAUD) yang terintegrasi dengan antar perawatan kesehatan masyarakat pos, misalnya pos program pendidikan bagi anak- anak di usia dini (PAUD) Teratai sejak terakhir dua tahun. (Noviawati, 2009). 
Selama kurun waktu tahun 2004-2009 capaian Angka Partisipasi Kasar (APK) PAUD naik sebesar 14,61\% (sekitar $39,09 \%$ tahun 2004 menjadi sekitar $53,70 \%$ tahun 2009) atau rata-rata 2,9\% per tahun. Berdasarkan studi pendahuluan yang dilakukan ditemukan anak yang mengikuti PAUD mempunyai perkembangan "sesuai" berjumlah 5 anak, sedangkan Perkembangan "meragukan" berjumlah 3 anak, dan tidak ada anak yang mengalami penyimpangan. Sedangkan untuk anak yang tidak mengikuti PAUD sejumlah 8 anak dikumpulkan di rumah peneliti dan hanya ada 2 anak yang mampu melaksanakaan tes KPSP yang diberikan. Sedangkan yang lainnya berjumlah 3 dengan perkembangan "meragukan" dan 3 anak yang mengalami perkembangan"ada penyimpangan".

Pendidikan anak memang harus dimulai sejak dini, agar anak bisa mengembangkan potensinya secara optimal. Dengan anak mengikuti pendidikan prasekolah seperti playgroup anak memiliki kematangan sosial yang baik dimana anak menjadi lebih mandiri, disiplin, dan mudah diarahkan untuk menyerap ilmu pengetahuan secara optimal (Wulandari, 2009). Berdasarkan data diatas, maka pemerintah daerah harus memperluas berbagai fasilitas yang mendukung lingkungan pembelajaran berkualitas bagi anak usia dini sehingga dapat dinikmati setiap masyarakat di wilayahnya masing-masing. Pendidikan anak usia dini dapat berjalan baik jika semua pihak dapat saling bekerja sama.

2. Rumusan Masalah

"Adakah Pengaruh Pendidikan PAUD Terhadap Tingkat Perkembangan Anak Usia Todler di PAUD Diponegoro Dsn. Pucanganom Ds. Sukorejo Kec. Gurah Kab. Kediri?"

3. Tujuan Penelitian

Mengetahui Perbedaan

Perkembangan Anak Usia Toodler Yang
Mengikuti Pendidikan PAUD dan Tidak Mengikuti PAUD Di Dsn. Pucanganom Ds. Sukorejo Kec. Gurah Kab. Kediri

\section{METODE PENELITIAN}

Dalam penelitian ini menggunakan jenis penelitian analitik komparatif dengan menggunakan pendekatan cross sectional. Populasi dalam penelitian adalah anak usia toodler $(1-3$ th $)$ di Dsn. Pucanganom Ds. Sukorejo Kec. Gurah Kab. Kediri sejumlah 41 anak. Sedangkan yang menjadi sampel dalam penelitian ini yaitu anak usia $1-3$ th di RW. 5 Dsn. Pucanganom Ds. Sukorejo Kec. Gurah Kab. Kediri yang memenuhi kriteria inklusi sejumlah 26 anak. Tahap pertama yang dilakukan oleh peneliti setelah pengumpulan data adalah editing data, yaitu klarifikasi data dengan observer lain jika terjadi sesuatu yang meragukan. Data yang terkumpul dari hasil pengamatan dipilah-pilah berdasarkan kelompok usia responden. Untuk memudahkan menganalisa data, maka peneliti menggunakan Coding sebagai berikut :

1. Kode responden

$\mathrm{A} 1, \mathrm{~A} 2, \mathrm{~A} 3$, dst....: responden yang PAUD pertama, dan seterusnya

B1, B2, B3, dst......: responden yang tidak mengikuti PAUD, dan seterusnya

2. Kode anak

$\mathrm{P}$ : anak yang mengikuti PAUD

TP: anak yang tidak ikut PAUD

3. Kode klasifikasi kategori

$\mathrm{S}$ : perkembangan sesuai

$\mathrm{M}$ : perkembangan meragukan

$\mathrm{P}$ : perkembangan ada penyimpangan

Tahap selanjutnya yaitu scoring kemudian setelah semua data terkumpul peneliti melakukan tabulasi/ pengelompokan data yang akan diteliti dengan menggunakan rumus Mann Whitney $U$-Test. 
HASIL DAN PEMBAHASAN

HASIL PENELITIAN

Tabel 1.1 Distribusi responden berdasarkan Perkembangan anak usia 1- 3 th yang mengikuti PAUD

\begin{tabular}{|l|l|l|l|}
\hline \multirow{2}{*}{ No } & Perkembangan & \multicolumn{2}{|c|}{ PAUD } \\
\cline { 3 - 4 } & & Jumlah & $\begin{array}{l}\text { Prosentase } \\
\%\end{array}$ \\
\hline 1. & Sesuai & 8 & 80 \\
\hline 2. & Meragukan & 2 & 20 \\
\hline 3. & Penyimpangan & 0 & 0 \\
\hline \multicolumn{2}{|l|}{ Jumlah } & 10 & 100 \\
\hline
\end{tabular}

Sumber data: Kuesioner

Berdasarkan data dari tabel di atas bahwa hampir seluruhnya (80\%) anak usia (1-3 tahun) yang mengikuti Pendidikan Anak Usia Dini mencapai perkembangan yang sesuai.

Tabel 1.2 Distribusi Responden Berdasarkan Perkembangan Anak Usia Toodler Yang Tidak Mengikuti PAUD

\begin{tabular}{|l|l|l|l|}
\hline No & Perkembangan & \multicolumn{2}{|c|}{ TIDAK PAUD } \\
\cline { 3 - 4 } & & Jumlah & $\begin{array}{l}\text { Prosentase } \\
\%\end{array}$ \\
\hline 1. & Sesuai & 5 & 31,25 \\
\hline 2. & Meragukan & 10 & 62,5 \\
\hline 3. & Penyimpangan & 1 & 6,25 \\
\hline \multicolumn{2}{|l|}{ Jumlah } & 16 & 100 \\
\hline
\end{tabular}

Sumber data: Kuesioner

Berdasarkan data dari tabel di atas bahwa sebagian besar $(62,5 \%)$ anak usia (1-3 tahun) yang tidak mengikuti Pendidikan Anak Usia Dini mencapai perkembangan yang meragukan.
Tabel $\quad 1.3$ Distribusi Perbedaan Perkembangan Anak Usia Toodler Yang Mengikuti PAUD dan Tidak Mengikuti PAUD

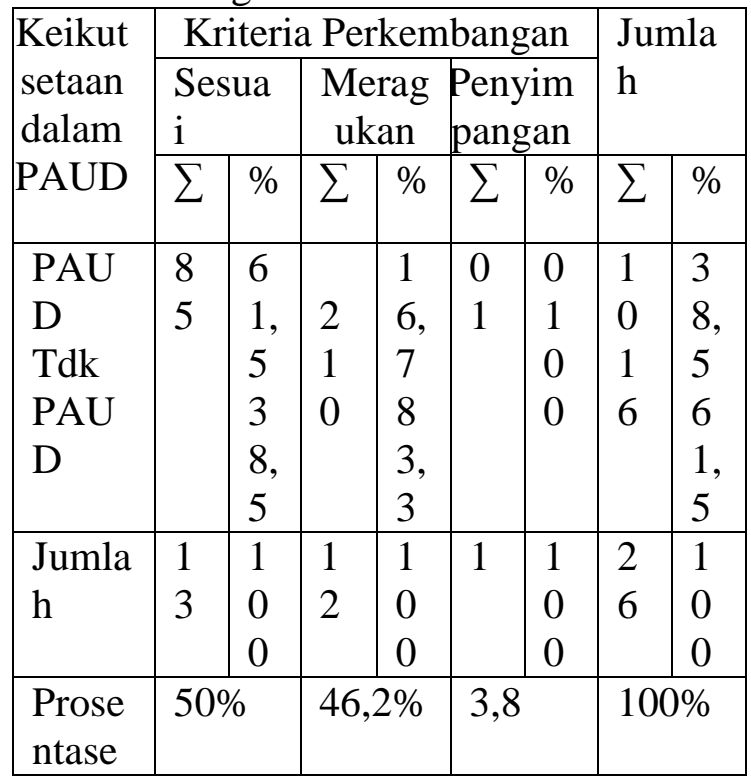

Sumber data: Kuesioner

Dari tabel silang diatas didapatkan anak yg mengikuti PAUD sebagian besar $(61,5 \%)$ mempunyai perkembangan sesuai, sedangkan anak yang tidak mengikuti PAUD didapatkan hampir seluruh $\quad(83,3 \%) \quad$ mempunyai perkembangan yang meragukan.

Untuk mengetahui ada tidaknya perbedaan, selanjutnya akan diuji dengan menggunakan Uji Mann Whitney U-Test. Tabel 1.4 Hasil Uji Analisis Mann Whitney U-Test

\begin{tabular}{|l|l|l|l|l|}
\hline $\begin{array}{l}\text { Perkemb } \\
\text { angan } \\
\text { Anak }\end{array}$ & $\mathrm{N}$ & $\begin{array}{l}\text { Mea } \\
n \\
\text { Ran } \\
k\end{array}$ & $\begin{array}{l}\text { Sum } \\
\text { of } \\
\text { Rank }\end{array}$ & $\begin{array}{l}\text { Asymp.S } \\
\text { ig }\end{array}$ \\
\hline PAUD & 10 & $\begin{array}{l}17,5 \\
0\end{array}$ & $\begin{array}{l}175.0 \\
0\end{array}$ & 0,017 \\
\cline { 1 - 3 } $\begin{array}{l}\text { Tidak } \\
\text { PAUD }\end{array}$ & 16 & $\begin{array}{l}11,0 \\
0\end{array}$ & $\begin{array}{l}176.0 \\
0\end{array}$ & \\
\hline
\end{tabular}

Dari tabel tersebut ditemukan bahwa nilai Asymetri signifikan adalah 0,017. Nilai Asymetri Signifikan tersebut lebih kecil dari nilai $\alpha=0,05$ yang artinya ada perbedaan yang bermakna antara anak yang mengikuti PAUD dan tidak mengikuti PAUD. 


\section{PEMBAHASAN}

a) Perkembangan Anak Yang Mengikuti Pendidikan Anak Usia Dini

Berdasarkan hasil penelitian yang dilakukan didapatkan hampir seluruh anak usia (1-3 tahun) mengalami perkembangan yang sesuai mencapai (80\%). Perkembangan anak yang mengikuti Pendidikan Anak Usia Dini mencapai perkembangan yang sesuai, itu dikarenakan pada Pendidikan Anak Usia Dini terdapat tempat yang kondusif, berorientasi pada kebutuhan anak, serta ditunjang dengan tempar bermain yang memadai. Dimana hal tersebut dapat merangsang tumbung kembang anak secara optimal.

b) Perkembangan Anak yang tidak

mengikuti Pendidikan Anak Usia Dini

Dari hasil penelitian yang telah dilakukan didapatkan bahwa sebagian besar anak usia 1-3 tahun yang tidak mengikuti PAUD mengalami perkembangan yang meragukan mencapai $(62,5 \%)$. Kurangnya peran orang tua dalam mendidik dan mengarahkan anak pada arah yang tepat dapat mempengaruhi perkembangan anak. Padahal pendidikan anak usia dini dapat berlangsung dimana saja dan kapan saja seperti halnya interaksi manusia yang terjadi di dalam keluarga, teman sebaya, dan dari hubungan kemasyarakatan yang sesuai dengan kondisi dan perkembangan anak usia dini (Dida, 2010).

c) Perbedaan Perkembangan Anak Usia Toodler Yang Mengikuti Pendidikan Anak Usia Dini (PAUD) dan Tidak Mengikuti Pendidikan Anak Usia Dini (PAUD)

Berdasarkan hasil uji Wilcoxon Mann Whitney U-Test tentang perkembangan anak yang mengikuti Pendidikan Anak Usia Dini dan tidak mengikuti Pendidikan Anak Usia Dini di PAUD Diponegoro Dsn. Pucanganom Ds. Sukorejo Kec. Gurah Kab. Kediri, didapatkan nilai Asygmetri Signifikan sebesar 0,017. Dapat diambil kesimpulan bahwa terdapat perbedaan antara perkembangan anak yang mengikuti Pendidikan Anak Usia Dini dan tidak mengikuti Pendidikan Anak Usia Dini. Anak yang mengikuti Pendidikan anak usia dini mencapai perkembangan yang sesuai, dikarenakan mereka mengikuti pendidikan di lembaga formal yang memiliki tempat yang kondusif, alat permainan yang lengkap serta sistem pengajaran yang teratur. Hal ini sesuai dengan pernyataan Kuntjojo (2010) yang menyebutkan bahwa Pendidikan anak usia dini pelaksanaannya menggunakan prinsip berorientasi pada kebutuhan anak, belajar melalui bermain, menggunakan lingkungan yang kondusif, serta menggunakan pembelajaran terpadu. Dapat disimpulkan bahwa jika anak mengikuti Pendidikan anak usia dini maka mereka akan mendapatkan stimulasi yang lebih terarah yang akan berdampak baik bagi perkembangannya.

Sedangkan anak yang tidak mengikuti program Pendidikan anak usia dini mencapai perkembangan meragukan dikarenakan mereka kurang mendapatkan latihan atau pendidikan yang terarah. Padahal pendidikan anak usia dini dapat berlangsung dimana saja dan kapan saja seperti halnya interaksi manusia yang terjadi di dalam keluarga, teman sebaya, dan dari hubungan kemasyarakatan yang sesuai dengan kondisi dan perkembangan anak usia dini (Dida, 2010).

\section{KESIMPULAN DAN SARAN}

Ada perbedaan yang signifikan antara perkembangan anak yang mengikuti Pendidikan anak usia dini dan tidak mengikuti Pendidikan Anak Usia Dini. Diharapkan orang tua lebih meluangkan waktu dan memberikan pendidikan dan latihan pada anaknya secara terarah, dan lebih baik lagi apabila anak diikutkan dalam program pendidikan anak usia dini.

\section{DAFTAR PUSTAKA}

2006. Ilmu Kesehatan Anak. Jakarta: Salemba Medika 
Alimul,

Aziz.

2003

Riset

Keperawatan dan Teknik

Penulisan

Ilmiah.

Jakarta:Salemba Raya

Arikunto, S. 2006. Prosedur Penelitian

Suatu Pendekatan Praktik.

Jakarta: PT Rineka Cipta

Dida.(2010).http://sadidadalila.wordpress.

com/2010/01/03/pentingnya-

pendidikan -anak- usia-dini-di-

indonesia/. (diakses pada tanggal 15 Maret 2015)

Depkes RI. (2006).

Pedoman

Pelaksanaan Stimulasi, Deteksi dan Intervensi Dini Tumbuh Kembang Anak Di Tingkat Pelayanan Kesehatan Dasar. Jakarta: Depkes RI

Fajar, Ibnu, dkk. 2009. Statistika untuk Praktisi Kesehatan. Yogyakarta: Graha Ilmu

Hasan, Maimunnah. (2010). Pendidikan Anak Usia Dini. Jogjakarta: Diva Press

Kania. 2006. Stimulasi Tumbuh Kembang Anak Untuk Mencapai Tumbuh Kembang Yang Optimal. http://pustaka.unpad.ac.id/. Diakses 15 Maret 2015.

Kuntjojo. (2010). Konsep-konsep Dasar Pendidikan Anak Usia

Dini.http://kunt34.blogspot.com/ 2010/11/konsep-konsep-dasarpendidikan- anak.html (diakses pada tanggal 21 Maret 2015)

Narendra, Moersintowarti B, dkk. (2002). Buku Ajar Tumbuh Kembang Anak dan Remaja. Jakarta: Sagung Seto

Notoatmodjo, S. 2010. Metodologi Peneletian Kesehatan. Jakarta : PT Rineka Cipta.

Nursalam, 2008. Konsep Penerapan dan Metodologi Penelitian Ilmu Keperawata. Jakarta: Salemba Medika.

Mansur, H. (2009). Psikologi Ibu dan Anak untuk Kebidanan. Jakarta : Salemba Medika
Mulyasa, H. (2012). Manajemen PAUD. Bandung : PT Remaja Rosdakarya

Santrock, J.W. (2007). Perkembangan Anak Edisi 11 Jilid 1. Jakarta : Erlangga

Soetjiningsih. (2002). Tumbuh Kembang Anak. Jakarta : EGC

Sugiyono. (2011). Statistik Untuk Penelitian. Bandung : $\mathrm{CV}$ Alfabeta

Wong, Donna L. (2003). Pedoman Klinis Pediatrik. Jakarta : EGC 